\title{
Etiological and Clinical Profile of Seizures in Late Preterm and Term Neonates - A Retrospective Study in an Intramural Tertiary Care Centre
}

\author{
Venkatesh G', V Prakash ${ }^{2}$, Mohd Sajjid², Elango ${ }^{3}$ \\ ${ }^{1}$ DM Neonatology Resident, Dept of Neonatology, IOG, MMC, Chennai- 600008, Tamil Nadu, India, ${ }^{2}$ Assistant professor, Dept of Neonatology, IOG, MMC, Chennai- \\ 600008 ,Tamil Nadu, India, ${ }^{3}$ Professor and HOD Dept of Neonatology, IOG, MMC, Chennai- 600008,Tamil Nadu, India.
}

\section{Abstract}

Background: Seizures represents the most distinctive signal of the neurological disease in the newborn period. Neonatal seizures are associated with unfavourable short and long term neurodevelopmental outcome. Objective: Our study was aimed at finding incidence, etiological factors, and clinical profile seizures in late preterm and term infants. Subject and Method: A retrospective study was conducted in an intramural tertiary care hospital, IOG, Chennai, India. Detailed antenatal, intrapartum history and baseline characteristics of both mother and infants, clinical details of seizures, investigations and neuroimaging details of 113 late preterm and term neonates with seizures data was collected from January 2018 to December 2018. Results: The incidence of seizures in late preterm and term neonates was $0.76 \%$ in our study. Hypoxic ischemic encephalopathy (HIE) was the commonest etiology (50.4\%) followed by sepsis(24.8\%). Majority of HIE neonates presented within $12 \mathrm{hrs}$ of life (89\%). Hypoglycemia (21.2\%) was the commonest primary metabolic abnormality followed by hypocalcemia (9.7\%). Clonic type was the most commonest type $(82.3 \%)$ of seizure followed by subtle (73.5\%) seizure. Conclusion: Hypoxic ischemic encephalopathy was the commonest etiology along with clonic seizures most commonest types. Hypoglycemia was the most commonest biochemical abnormality.

Keywords: Hypoglycemia, Hypocalcemia, HIE, Sepsis, Seizures, Preterm.

Corresponding Author: Dr. V Prakash, Assistant professor, Dept of Neonatology, IOG, MMC, Chennai- 600008, Tamil Nadu, India. Email: venkathpt2000@gmail.com

Received: January 2020

Accepted: January 2020

\section{Introduction}

Seizures represent the most distinctive signal of neurological disease in the newborn period. ${ }^{[1]}$ It is often difficult to diagnose all seizure activity especially subtle seizures and more difficult if it is associated with electroclinical dissociation.

The overall incidence of neonatal seizures was 2.1 per 1000 live-born infants The incidence of neonatal seizures was lowest (1.7/1000) at 37-41 gestational weeks (GW) and increased in both preterm $(21.9 / 1000$ at $25-28 \mathrm{GW})$ and post term deliveries $(3.0 / 1000$ at $\geqslant 42 \mathrm{GW}) .{ }^{[2]}$ According to few Indian studies incidence varies between $1.5 \%-14 \%{ }^{[3]}$

Neonatal seizures are associated with unfavorable short and long term developmental outcomes. ${ }^{[4]}$ More than $50 \%$ of survivors experience considerable disability across a range of epilepsy, and/ or intellectual disability, ${ }^{[4,5]}$ and require costly and lifelong and social and academic support. Neonatal seizure is a clinical emergency where rapid diagnosis and prompt treatment is required. Delay may result in poor neurological outcome. Etiology of seizure should be diagnosed and specific treatment can be given which reduces chances of recurrence. Prognosis is determined by the etiology of the neonatal seizures. If the
EEG background is normal, the prognosis is excellent for seizures to resolve; normal development is likely. ${ }^{[6,7]}$

Historically seizures were divided in following clinical categories viz. focal clonic, multifocal clonic, tonic,myoclonic, \& subtle seizures. ${ }^{[1]}$ Diverse medical conditions in the newborn can be associated with neonatal seizures. Hypoxia-ischemia is nonetheless traditionally considered the most common cause of neonatal seizures ${ }^{[1,8]}$

Cerebral infarction and stroke the second most common cause of neonatal seizures occurs in otherwise well term infants, without previous risk factors ${ }^{[9,10]}$ and involves left middle cerebral artery territory and presents with right sided clonic seizures. Intracranial hemorrhage is implicated in $10 \%$ to $15 \%$ of seizures, and amongst them Intra-ventricular hemorrhage or Periventricular hemorrhagic infarction is the most common Intracranial hemorrhage in preterm infants and constitutes around $45 \%$ seizures in preterm. ${ }^{[1,12]}$

Central nervous system infections during intrapartum or postnatal period can be associated with seizures. ${ }^{[13]}$ Biochemical disturbances occur frequently in neonatal seizures either as an underlying cause or as an associated abnormality. ${ }^{[14,15]}$ Metabolic disturbances could be more commonly transient and rapidly correctable or less commonly inherited as persistent causes. Infants of diabetic mothers, small for gestational age infants, infants with birth 


\section{Venkatesh et al; Etialagical and Clinical Profile of Seizures in Late $\mathcal{P}$ reterm and $\mathcal{T}$ erm Neanates}

asphyxia are at more risk of hypoglycemia. Late onset hypocalcaemia due to use of high phosphate infant formula has been cited as common cause of seizures. ${ }^{[16,17]}$ However commonly hypocalcaemia occurs in infants with trauma, hemolytic disease, asphyxia and IDM and usually coexists with hypoglycemia and hypomagnesemia ${ }^{[18]}$

and presents at 2-3 days of life.

Hypomagnesaemia with serum $<1.5 \mathrm{mg} / \mathrm{dl}$ can occasionally manifest with tetany and seizures at 2-4weeks of age and has secondary hypocalcaemia associated.

Hypophosphatemia may be caused by ingestion of milk formulas containing high amounts of phosphorous, excessive parenteral administration of phosphorus, impaired renal function, and hypoparathyroidism. ${ }^{[19]}$

Hyponatremia as a result of fluid overload renal compromise and SIADH (syndrome of inappropriate ADH secretion) can be a frequent complication of birth asphyxia and could complicate the management of seizures in this condition. ${ }^{[20]}$

\section{Subjects and Methods}

A retrospective study was conducted in an intramural tertiary care hospital NICU, Institute of Obstetrics and Gynaecology, Chennai from January 2018 to December 2018. Maternal and neonatal data in the following order was collected from Medical Record Department of IOG.

\section{Inclusion criteria}

All Neonate with more than 34 weeks of gestation with seizures.

\section{Exclusion criteria}

Neonate less than 34weeks of gestation.

Neonates without seizures.

\section{Data collection procedure}

Maternal age, parity, associated risk factors like Gestational or type1/2 Diabetes mellitus, Pregnancy induced hypertension, eclampsia, primary hypertension, hypothyroidism, chronic heart and kidney diseases, connective tissue disorders, Rheumatic heart disease, seizure disorders,fever,urinary tract infection, chorioamnionitis, intrauterine infections(TORCH), abnormal antenatal scan findings, on drugs like anti epileptics, antihypertensive, insulin, metformin, drug withdrawl, events such as antepartum hemorrhage, intrapatrtum events like CTG monitoring, prolonged $2^{\text {nd }}$ stage of labour, mode of delivery, assisted or normal delivery, indication for cesarean section were noted and collected.

Neonatal baseline data like sex, birth weight, gestational age, mode of delivery, APGAR, resuscitation requirement, birth asphyxia, perinatal trauma. Infants divided like small for gestational age(SGA), appropriate for gestational age(AGA), large for gestational age(LGA) along with head circumference and Intrauterine growth retardation (IUGR) status by using appropriate growth charts. Different types of seizures like clonic, tonic, myoclonic and generalized tonic clonic data were collected along with time of onset of seizure, duration of seizure, capillary blood glucose(CBG) at time of seizure, frequency of seizure . Investigation during seizure episode like CBG, Calcium, sodium, potassium, urea, creatinine, sepsis screen and blood culture were collected . Special investigations like magnesium, phosphorus, CSF examination, CSF culture, IEM work up like TMS, neuroimaging such as ultrasongarphy of cranium for cerebral malformation, IVH/ICH,asphyxia changes etc were collected. CT and MRI brain for perinatal asphyxia, cerebral malformation, intracranial hemorrhage,intracranial infection were collected. Treatment data for seizure in the form of dextrose infusion for hypoglycemia, calcium infusion, AED like phenobarbitone, phenytoin, levitiracetam, midazolam, maximum dose required for each of AED to control seizure, whether seizures controlled or not data was collected. Whether baby was discharged or died in the hospital and how long the duration of stay in the hospital data was also collected.

\section{Criteria for diagnosing various biochemical}

\section{abnormalities: ${ }^{20}$}

Hypoglycemia: blood sugar $<40 \mathrm{mg} / \mathrm{dl}$ (normal range 40 $150 \mathrm{mg} / \mathrm{dl}$ )

Hypocalcaemia: total serum calcium $<7 \mathrm{mg} / \mathrm{dl}$ (normal range $7-10 \mathrm{mg} / \mathrm{dl}$ ) Or Ionized calcium $<4 \mathrm{mg} / \mathrm{dl}$ (normal range $4-5.5 \mathrm{mg} / \mathrm{dl}$ )

Hypomagnesaemia: serum magnesium $<1.5 \mathrm{mg} / \mathrm{dl}$ (normal range: $1.5-1.8 \mathrm{mg} / \mathrm{dl}$ )

Hypernatremia: serum sodium $>150 \mathrm{meq} / \mathrm{dl}$ (normal range $130-150 \mathrm{meq} / \mathrm{dl}$ )

Hyponatremia: serum sodium $<130 \mathrm{meq} / \mathrm{dl}$

Hypokalemia: serum potassium $<3.5 \mathrm{meq} / \mathrm{dl}$ (normal range $3.5-5.5 \mathrm{meq} / \mathrm{dl})$

Hyperkalemia: serum potassium $>5.5 \mathrm{meq} / \mathrm{dl}$

Hyperphosphatemia: serum phosphorus $>8 \mathrm{mg} / \mathrm{dl}$ (normal range $6-8 \mathrm{mg} / \mathrm{dl}$ )

In addition complete blood counts, band cell count, absolute neutrophil count, CRP, blood culture, USG cranium, $\mathrm{MRI} / \mathrm{CT}$, and CSF analysis were done as per the requirement in individual cases.

\section{Statistical analysis}

Data was described as mean \pm SE and \%age. Software used for data analysis was SPSS 16.0 (statistical package for social sciences) and MS Excel.

\section{Results}

Table 1: Gestational age

\begin{tabular}{|l|l|l|}
\hline GA & n & Percentage \\
\hline$\geq 34-<37$ wks & 12 & $10.6 \%$ \\
\hline$\geq 37$ wks & 101 & $89.4 \%$ \\
\hline Total & 113 & $100 \%$ \\
\hline
\end{tabular}

Table 2: Weight

\begin{tabular}{|l|l|l|}
\hline & n & Percentage \\
\hline AGA & 53 & $46.9 \%$ \\
\hline SGA & 56 & $49.6 \%$ \\
\hline LGA & 4 & $3.5 \%$ \\
\hline Total & 113 & $100 \%$ \\
\hline
\end{tabular}




\section{Venkatesh et al; Etialagical and Clinical Profile of Seizures in Late Preterm and Jerm Neanates}

Neonates who had seizures, 12 were late preterm and 101 were term neonates. According to weight 56, 53 and 4 neonates were SGA, AGA and LGA neonates respectively.

\section{Table 3: Gender}

\begin{tabular}{|l|l|l|}
\hline Sex & n & Percentage \\
\hline Male & 71 & $62.8 \%$ \\
\hline Female & 42 & $37.2 \%$ \\
\hline Total & 113 & $100 \%$ \\
\hline
\end{tabular}

Male gender predominant among neonates who had seizures with 71 neonates $(62.8 \%)$ followed by female 42 neonates $(37.2 \%)$.

\section{Table 4: APGAR score}

\begin{tabular}{|l|l|l|}
\hline APGAR 5 min & n & Percent \\
\hline$<7$ & 57 & $50.4 \%$ \\
\hline$>7$ & 56 & $49.6 \%$ \\
\hline
\end{tabular}

Among infants who had seizures had APGAR score of $<7$ at 5 min were $57(50.4 \%)$.

\section{Table 5: Maternal baseline characteristics}

\begin{tabular}{|l|l|l|}
\hline Age & n & Percent \\
\hline $18-22$ & 53 & $46.9 \%$ \\
\hline $23-27$ & 28 & $24.85 \%$ \\
\hline $28-32$ & 24 & $21.25 \%$ \\
\hline$>32$ & 08 & $7.1 \%$ \\
\hline Total & 113 & $100 \%$ \\
\hline
\end{tabular}

\begin{tabular}{|l|l|l|}
\hline Table 6: Parity & Percentage \\
\hline Parity & n & $70.8 \%$ \\
\hline Primi gravida & 80 & $29.2 \%$ \\
\hline Multi gravid & 33 & $100 \%$ \\
\hline Total & 113 & \\
\hline
\end{tabular}

\section{Table 7: Maternal risk factors}

\begin{tabular}{|c|c|c|c|}
\hline \multicolumn{2}{|c|}{ Risk factors } & $\mathbf{n}$ & Percent \\
\hline \multicolumn{2}{|l|}{ PIH } & 56 & $49.6 \%$ \\
\hline \multicolumn{2}{|c|}{ GDM/DM } & 11 & $9.7 \%$ \\
\hline \multicolumn{2}{|c|}{ Chorioamnionitis } & 00 & 00 \\
\hline \multicolumn{2}{|c|}{ Hypothyroid } & 18 & $16 \%$ \\
\hline \multicolumn{2}{|l|}{ Fever } & 01 & $0.9 \%$ \\
\hline \multicolumn{2}{|l|}{ UTI } & 02 & $1.8 \%$ \\
\hline \multicolumn{2}{|c|}{ Oligohydramnios } & 05 & $4.4 \%$ \\
\hline \multicolumn{2}{|c|}{ Others $^{*}$} & 07 & $6 \%$ \\
\hline \multirow[t]{2}{*}{ MOD } & NVD/ANVD & 52 & $46 \%$ \\
\hline & LSCS & 61 & $54 \%$ \\
\hline
\end{tabular}

*Mothers with connective tissue disorders, pulmonary TB, arthralgia,

Rheumatic heart disease.

Around 53(46.9\%) of mothers were in the age group of 18$22 \mathrm{yrs}$, and most of them were primi gravida 80(49.6\%). Most common maternal risk factor for the mothers of neonates with seizure was PIH.

Total number of term and late preterm deliveries during the study period was 14898 , of which 4377 neonates were admitted to NICU. A total of 113 late preterm and term neonates had seizure. The overall incidence of seizures among late preterm and term neonates was $0.76 \%$ and incidence of seizure among late preterm and term neonates admitted to NICU was $2.6 \%$.

\section{Table 8: Age on admission}

\begin{tabular}{|l|l|l|}
\hline Age in hrs & n & Percent \\
\hline $1-12 \mathrm{hrs}$ & 58 & $51.3 \%$ \\
\hline $12-24 \mathrm{hrs}$ & 20 & $17.7 \%$ \\
\hline$>24 \mathrm{hrs}$ & 35 & $31 \%$ \\
\hline Total & 113 & $100 \%$ \\
\hline
\end{tabular}

Age on admission for neonates who presented with seizure or later on developed seizure during hospital stay varied between $0-25$ days with mean value of $24.47 \pm 4.53 \mathrm{hrs}$. The first day onset of seizure had significant correlation with etiology, almost all perinatal asphyxia with HIE neonates presented with seizures within $24 \mathrm{hrs}$ of life. Neonates with hypocalcemia and sepsis presented after $24 \mathrm{hrs}$ of life.

Table 9: Etiology of neonatal seizures

\begin{tabular}{|l|l|l|}
\hline Etiology & n & Percent \\
\hline HIE & 57 & $50.4 \%$ \\
\hline Septicemia(Meningitis) & 28 & $24.8 \%$ \\
\hline Hypoglycemia & 24 & $21.2 \%$ \\
\hline Hypocalcemia & 11 & $9.7 \%$ \\
\hline IVH & 02 & $1.8 \%$ \\
\hline IEM & 02 & $1.8 \%$ \\
\hline Unknown etiology & 02 & $1.8 \%$ \\
\hline
\end{tabular}

The most common etiology in our study was Hypoxic ischemic encephalopathy followed by sepsis and metabolic problems. Many neonates had overlapping etiology especially HIE along with hypocalcemia and hypoglycemia.

Table 10: Type of neonatal seizures

\begin{tabular}{|l|l|l|}
\hline Type & Frequency & Percent \\
\hline Clonic & 93 & $82.3 \%$ \\
\hline Tonic & 14 & $12.4 \%$ \\
\hline Myoclonic & 4 & $3.5 \%$ \\
\hline GTC & 3 & $2.7 \%$ \\
\hline Subtle & 83 & $73.5 \%$ \\
\hline
\end{tabular}

The most commonest type of seizure was clonic (82.3\%) followed by subtle seizure (73.5\%). Many infants had more than one type of seizures.

\begin{tabular}{|c|c|c|}
\hline AED/Treatment & $\mathbf{n}$ & Percent \\
\hline Phenobarbitone & 80 & $70.8 \%$ \\
\hline Pheno+Phenyt & 22 & $19.5 \%$ \\
\hline Pheno+Phenyt+ Levit & 04 & $3.5 \%$ \\
\hline Dextrose & 04 & $3.5 \%$ \\
\hline Calcium & 03 & $2.7 \%$ \\
\hline
\end{tabular}

Most of the neonates around $70.8 \%(80)$ were responded to single AED Phenobarbitone, only fewer $(04,3.5 \%)$ required more than two AED's.

Table 12: Duration of hospital stay

\begin{tabular}{|l|l|l|}
\hline Days & n & Percent \\
\hline $1-5$ days & 16 & $14.2 \%$ \\
\hline $6-10$ days & 24 & $21.2 \%$ \\
\hline $11-15$ days & 19 & $16.8 \%$ \\
\hline$\geq 16$ days & 54 & $47.8 \%$ \\
\hline Total & 113 & $100 \%$ \\
\hline
\end{tabular}




\section{Venkatesh et al; Etialagical and Clinical Profile of Seizures in Late $\mathcal{P}$ reterm and $\mathcal{T}$ erm Neanates}

Around $47.8 \%$ ( 54) neonates had to stay in the hospital for more than 15 days with mean value of $13.87 \pm 6.67$ days.

\section{Discussion}

The occurrence of seizures may be the first indication of neurological disorder and the time of onset of seizures has a significant correlation with the etiology of seizures and prognosis. Developmental immaturity influences many aspects of diagnosis, management and prognosis of seizure in newborn. The overall incidence of seizures in our study was $0.76 \%$ which is very low mainly because we have not included preterm neonates of less than 34 weeks of gestation which contribute major percentage of seizures. Our center has no EEG monitoring, we have to detect seizure clinically and is most subjective especially subtle seizures, have to depend on ability of hospital staff and duty resident for detection of seizure, which has more inter variability which will lead sometimes over diagnosis and sometimes under diagnosis of seizure.

In our study 58 neonates( 51.3\%) had seizure within $12 \mathrm{hrs}$ of life, most of them attributed to perinatal asphyxia with HIE. Rose et $\mathrm{al}^{[17]}$ also foundearly onset seizures in 75 $(50.33 \%)$ babies whereas Coen RW et $\mathrm{al}^{[21]}$ found that $81 \%$ of babies had early onset seizures.

Frequency of birth asphyxia with HIE as a cause of seizures was $50.3 \%$ in our study. Sood A et al ${ }^{[15]}$ and Kumar A et al. reported that birth asphyxia as the etiology of seizures was seen in $45.71 \%$ and $48.2 \%$ cases respectively, which are quite comparable to results of our study. ${ }^{[20]}$

In our study sepsis was second most common cause of seizures accounting for $28(24.8 \%)$ cases. Out of 28 neonates 7 had meningitis and 12 neonates had culture positive sepsis. A study conducted by Legido A et $\mathrm{al}^{[22]}$ reported that out of 40 babies $17.2 \%$ had some kind ofinfection leading to fits. Bushraet al ${ }^{[23]}$ reported it as $34 \%$ comparable to our study. In our study clonic type (82.3\%) of seizure most common type followed by subtle(73.5\%). Many neonates had more than one type of seizures. Taksandeet al. ${ }^{[24]}$ showed subtle seizures as the commonest type of fits occurring in 50\% of neonates.

In our study 2 late preterm neonates had IVH, 2 term neonates suspected to have IEM. Etiology of two neonates with seizure could not be determined inspite of detailed workup.

In our study commonest maternal risk factor associated with mothers of neonates with seizures was PIH.

In our study most of the neonates responded to single AED around $70.8 \%$.Fewer neonates required more than 2 AED's.

\section{Conclusion}

Hypoxic ischemic encephalopathy was the commonest etiology of neonatal seizures in late preterm and term infants and in them most of the seizures had an onset in the first 12 hours of life. Sepsis was second most common cause of neonatal seizure in late preterm and term neonates. Overall clonic and subtle seizures were the commonest seizure types encountered. Hypoglycemia was the commonest biochemical abnormality in primary metabolic seizures.

\section{Acknowledgement}

I would like to thank my assistant professors for their guidance and unconditional support for doing this study.

\section{References}

1. Joseph J.Volpe, Neonatal seizures, Neurology of the newborn, $5^{\text {th }}$ ed. Saunder's; 2008: 203-204

2. L Hellstrom-Westas, I Amer- Wahlin,J Agren, K Kallen.Incidence and risk factors for neonatal seizures in Sweden,BMJ journals, Volume 93, Issue Supl2.

3. Grover N. Biochemical abnormalities in neonatal seizures. In: Manual abstracts of Pedicon. National conference of pediatrics. Mumbai : IAP. 2003: Neo/10:175

4. Uria-Avellanal C, Marlow N, Rennie JM. Outcome following neonatal seizures. Semin Fetal Neonatal Med 2013; 18:224-32.

5. Ronen GM, Buckley D, Penny S, Streiner DL. Long term prognosis in children with neonatal seizure : a population based study. Neurology 2007;69;1816-22.

6. Sheth RD. Frequency of neurologic disorders in neonatal intensive care unit. J Child Neuro.1 1998 Sep 13(9):424-8.

7. Sheth RD, Bodesteiner JB. Delayed postanoxic encephalopathy: possible role of apoptosis.J Child Neurol.1998. Sep 13(7):347-8.

8. Sarnat HB, Sarnat MS. Neonatal encephalography following foetal distress. A clinical and encephalographic study. Arch Neurol 1976; 33:696705.

9. Mercuri E, Cowan M, Rutherford D, Pennoch J,Dubowitz L. Ischemic and haemorrhagic brain lesions in new-borns with seizures and normal Apgar scores. Arch Dis Child 1995; 73:F67-F74.

10. Scher MS. Destructive brain lesion presumed foetal onset: Antepartum causes of cerebral palsy. Paediatrics. 1991;88:896-906

11. Scher MS, Hamid MY, Steppe DA.Ictal and interictal durations in preterm and the neonates. Epilepsia 1993;34:284-8

12. Sheth RD, Hobbs GR, Mullett M. Neonatal seizures:Incidence onset and etiology by gestational age. JPerinatol. 1999;19:40-3.

13. Kairam R, De Vivo DC. Neurologic manifestations of congenital infection. Clin Perinatol. 1981;8:45565.

14. Brown JK, Cockburn F. Clinical and chemical correlates in convulsions of the new-born. Lancet.1972;1;135-9

15. Sood A, Grover N, Sharma R. Biochemical abnormalities in neonatal seizures. Indian Journal ofPaed. 2003; 70(3):221-4.

16. Keen JH, Lee. Sequelae of neonatal convulsions. Study of 112 infants. Arch Dis Child 1973. Jul;48(7):542-546

17. Rose AL, Lombroso. CT: A study of clinical, pathological and electroencephalographic features in 137 full term babies with a long term follow up. Paediatrics 1970;45:404-425

18. Mark S. Scher. Avery's Disease of New-born 8thed.Elsevier Health Sciences; 2005. Chapter 66, Neonatal seizures, p1020.

19. Carole Kenner, Judy, Wright Lott. Comprehensive neonatal care 4th ed. Elsevier Health Sciences2007. Chapter 8, 95.

20. Kumar A, Gupta V, Singla: Biochemical abnormalities in neonatal seizures. Indian Paed. 1995; 32(4):424-8.

21. Coen RW, Mc Cutchen CB, Wermer D, Snyder J,Gluck FE. Continuous monitoring of EEG following perinatal asphyxia. J Pediatr 1982; 100:628-30.

22. Legido A, Clancy RR. Neurologic outcome after EEG proven neonatal seizures. Paediatrics 1991; 88:583-96.

23. Bushra AM, Butt MA. Seizure etiology in the newborn period. Journal of College of Physicians and Surgeons Pakistan 2005; 15:78690.

24. Taksande AM, Krishna V, Manish Jain, MahaveerL. Clinicobiochemical profile of neonatal seizures.PaedOncall Journal 2005 October; 2(10). 


\section{Venkatesh et al; Etialagical and Clinical Profile of Seizures in Late Preterm and Jerm Neanates}

Copyright: (C) the author(s), 2020. It is an open-access article distributed under the terms of the Creative Commons Attribution License (CC BY 4.0), which permits authors to retain ownership of the copyright for their content, and allow anyone to download, reuse, reprint, modify, distribute and/or copy the content as long as the original authors and source are cited.

How to cite this article: Venkatesh G, V Prakash, Sajjid M, Elango. Etiological and Clinical Profile of Seizures in Late Preterm and Term Neonates - A Retrospective Study in an Intramural Tertiary Care Centre. Asian J. Clin. Pediatr. Neonatol.2020;8(1):69-73.

DOI: dx.doi.org/10.47009/ajcpn.2020.8.1.17

Source of Support: Nil, Conflict of Interest: None declared. 